\title{
Fotossíntese em alfafa (Medicago sativa L.) sob supressão e ressuprimento de fosfato ${ }^{1}$
}

\author{
Photosynthesis in alfalfa (Medicago sativa $\mathrm{L}$.) under phosphate \\ suppression and ressuply
}

\author{
Fernando Teixeira Gomes ${ }^{1}$ Gilmara Duarte Pereira ${ }^{2}$ \\ Arnaldo Chaer Borges ${ }^{4}$ Paulo Roberto Mosquim ${ }^{5}$
}

\section{RESUMO}

Neste estudo, foram avaliados os efeitos da supressão e do ressuprimento de fosfato (Pi) sobre a fotossintese e eficiência fotoquímica de plantas de Medicago sativa $c v$. Flórida 77, em diferentes estádios do desenvolvimento vegetativo (V3, V4) e reprodutivo (R6, R8). O ensaio foi conduzido em casa de vegetação e as plantas cultivadas na solução nutritiva de HOAGLAND \& ARNON (1950), contendo $0,14 \mathrm{mmol}^{-1}$ de Pi. A supressão de Pi por dez dias reduziu os teores de fósforo nas folhas amostradas, em todos os estádios do desenvolvimento. Entretanto, com o ressuprimento, somente nos estádios vegetativos, os valores foram semelhantes ao tratamento controle. A fotossintese por área foliar, em todos os estádios do desenvolvimento diminuiu com a supressão de Pi. De modo geral, o ressuprimento de Pi à solução nutritiva resultou em recuperação na fotossintese, excetuando-se as plantas no estádio V3, uma indicação de que o periodo de supressão não causou danos permanentes no aparato fotossintético. Os teores dos pigmentos fotossintéticos e a eficiência fotoquímica do fotossistema II (FS II), avaliada pela relação $F_{v} / F_{m}$, não foram alterados quando as plantas foram submetidas à supressão de Pi. Esse resultado demonstra que o transporte de elétrons através do FS II não limitou a fotossintese nas folhas amostradas, sob supressão de Pi, sugerindo que a supressão causou efeito mais pronunciado na etapa bioquímica da fotossintese.

Palavras-chave: solução nutritiva, eficiência fotoquímica assimilação do $\mathrm{CO}_{2}$.

\section{ABSTRACT}

This work evaluated the phosphate (Pi) suppression and ressupply on photosynthesis and

\begin{abstract}
photochemical efficiency from Medicago sativa plants $c v$. Florida 77, in different growth stages (V3 and V4) and reproductive ( $R 6$ and $R 8)$. The experiment was performed in a greenhouse, the plants being cultivated in HOAGLAND \& ARMOND (1950) nutritive solution containing 0,14mmol $L^{-1}$ of Pi. Pi suppression for ten days reduced Pi levels in sampled leaves, in all growth stages. However, with the re-supply only in the vegetative stages the values were similar to the control treatments. Photosynthesis per foliar area in all growth stages decreased with Pi suppression. In general, Pi ressupply into the nutritive solution resulted in recovery of photosynthesis, except for $V 3$ plants, indicating that the suppression period did not cause permanent damage to the photosynthetic apparatus. Levels of photosynthetic pigments and the photosystem II (PS-II) photochemical efficiency evaluated as the Fv/Fm ratio were not altered when plants were submitted to Pi suppression. These results show that electons transport through PS-II did not limit photosynthesis in the sampled leaves under Pi supression, suggesting that Pi suppression caused a more pronunciated effect in the biochemical step of photosynthesis.
\end{abstract}

Key words: nutritive solution, photochemical efficiency, $\mathrm{CO}_{2}$ assimilation.

\section{INTRODUÇ̃̃̃O}

A disponibilidade de fosfato inorgânico (Pi) influencia o processo de fixação fotossintética do $\mathrm{CO}_{2}$ e altera o crescimento e o desenvolvimento das plantas (BROOKS, 1986; FREDEEN et al., 1989; QIU \& ISRAEL, 1994). Em algumas espécies vegetais, a

${ }^{1}$ Parte da tese apresentada pelo primeiro autor à Universidade Federal de Viçosa (UFV), para a obtenção do título de DS em Fisiologia Vegetal.

${ }^{2}$ Biólogo, DS, Embrapa-Gado de Leite, Juiz de Fora, MG. E-mail: ftgomes@zipmail.com.br. Autor para correspondência.

${ }^{3}$ Estudante de Agronomia, Bolsista de Iniciação Científica (CNPq), UFV.

${ }^{4}$ Engenheiro Agrônomo, PhD, Professor Titular, Departamento de Microbiologia, UFV.

${ }^{4}$ Engenheiro Agrônomo DS, Professor Titular, Departamento de Biologia Vegetal, UFV. 
deficiência de Pi limita a assimilação do $\mathrm{CO}_{2}$ e, em outras esse processo não é afetado (FOYER \& SPENCER, 1986; CRAFTS-BRANDNER, 1992b), dependendo do período de deficiência do Pi nas folhas, e também da capacidade da espécie em responder a baixos níveis internos de Pi (KONDRACKA \& RYCHTER, 1997). Assim, os efeitos da deficiência de Pi sobre a fotossíntese podem ser explicados em termos da ação de vários mecanismos regulatórios.

Sob baixos níveis de Pi, observou-se redução na fotossíntese em Glycine max, que pode estar associada à queda na atividade da ribulose 1,5bisfosfato carboxilase/oxigenase (rubisco) e na formação da ribulose 1,5-bisfosfato (RuBP) (FREDEEN et al., 1989; QIU \& ISRAEL, 1994). Baixa formação da RuBP pode afetar a fotossíntese, reduzindo a atividade de algumas enzimas do ciclo de Calvin, em particular da cinase da ribulose-5fosfato, e aumentar o influxo de carbono para a síntese de amido (FREDEEN et al., 1990). Em baixas concentrações, o Pi diminui a fotossíntese por causar maior efeito sobre a formação da RuBP, e não por limitação de ATP e NADPH (RAO \& TERRY, 1989). Observou-se que essa redução na formação da RuBP afetou mais a fixação fotossintética do $\mathrm{CO}_{2}$ sob condições de baixos níveis de Pi que a atividade da rubisco (FREDEEN et al., 1989).

Os estudos da influência do $\mathrm{Pi}$ em Glycine max e Zea mays sobre a taxa fotossintética e a partição de fotoassimilados, assim como seu papel na exportação de triose-fosfato através da membrana dos cloroplastos (FREDEEN et al., 1989; KHAMIS et al., 1990; QIU \& ISRAEL, 1994), demonstram que, à medida que o Pi tornase limitante, ocorre redução na quantidade de intermediários fosforilados do ciclo de Calvin e aumento na síntese de compostos de carbono livres de Pi. Em plantas de Phaseolus vulgaris, a deficiência do Pi reduziu a atividade fotossintética e essa redução foi parcialmente em função da ausência de compostos fosfatados. Após o ressuprimento do $\mathrm{Pi}$, ocorreu um rápido aumento no conteúdo desses compostos, com o conseqüente aumento da fotossíntese (SAWADA et al., 1983).

A fluorescência emitida pela clorofila $a$ reflete a eficiência das atividades fotossintéticas de maneira bastante complexa. A análise da cinética da fluorescência permite a avaliação de alguns parâmetros relacionados à capacidade de absorção e transferência de energia, principalmente os dependentes do estado de oxidação das moléculas do aceptor final do fotossistema II $\left(\mathrm{Q}_{\mathrm{A}}\right)$ e das mudanças conformacionais das membranas dos tilacóides (KRAUSE \& WEIS, 1991).
Em plantas de Glycine max, sob supressão e ressuprimento de $\mathrm{Pi}$, não foram observadas alterações significativas na cinética de emissão de fluorescência. Provavelmente, a distribuição de energia no complexo coletor de luz pela clorofila $a$ do FS II não foi afetada e a capacidade das clorofilas em absorver energia radiante permaneceu constante (SILVA, 1998). Este estudo objetivou avaliar os efeitos da supressão e do ressuprimento do fosfato $(\mathrm{Pi})$ sobre a atividade fotossintética e a cinética de emissão de fluorescência em plantas de Medicago sativa, em diferentes estádios do desenvolvimento.

\section{MATERIAL E MÉTODOS}

Sementes de Medicago sativa, cv. Flórida 77, fornecidas pela Embrapa Gado de Leite, Juiz de Fora, MG, foram previamente desinfestadas superficialmente por imersão em etanol $70 \%$ por 1 min e em peróxido de hidrogênio $6 \%(\mathrm{v}: \mathrm{v})$ por $5 \mathrm{~min}$, seguindo-se cinco lavagens em água destilada esterilizada (VINCENT, 1970). Após a desinfestação, elas foram germinadas em areia lavada e esterilizada. Quando atingiram o estádio de desenvolvimento V2 (folha trifoliolada, completamente desenvolvida no nó acima do nó das folhas unifolioladas), as plântulas foram selecionadas quanto à uniformidade de tamanho e, em seguida, foi efetuada a inoculação com Sinorhizobium meliloti.

Após a inoculação, duas plantas sob condições de casa de vegetação, foram cultivadas em vasos de isopor, com capacidade de 5,0 L, revestidos internamente com sacos de polietileno contendo solução nutritiva de HOAGLAND \& ARNON (1950) modificada, com a seguinte composição: K 3,0; Ca 3,0; Mg 1,0; P 0,14; S 2,0mmol L-1; B 46,0; Zn 1,5; $\mathrm{Cu}$ 0,3; Mo 0,6; Mn 18,0; Fe-EDTA 38,0 $\mathrm{mmol} \mathrm{L}^{-1}$. O $\mathrm{N}-\mathrm{NH}_{4} \quad 0,1$ e o $\mathrm{N}_{-} \mathrm{NO}_{3} 0,6 \mathrm{mmol} \mathrm{L}^{-1}$ somente foram adicionados à solução nutritiva na primeira semana de crescimento, e o Co, $0,75 \mathrm{mmol} \mathrm{L}^{-1}$, somente nas três primeiras semanas. Os vasos receberam aeração contínua e o $\mathrm{pH}$ da solução nutritiva foi ajustado diariamente em 6,0 \pm 0,3, mediante a adição de $\mathrm{HCl}$ $1,0 \mathrm{~N}$ ou $\mathrm{NaOH} 1,0 \mathrm{~N}$. As trocas de solução nutritiva foram efetuadas semanalmente durante a fase vegetativa e no intervalo de três dias durante a fase reprodutiva.

Foram executados dois ensaios. O primeiro foi realizado para investigar os efeitos da supressão do $\mathrm{Pi}$, durante os estádios vegetativos V3 (folhas completamente desenvolvidas no $5^{\circ}$ nó acima do nó das folhas unifolioladas) e V4 (folhas completamente desenvolvidas no 7ํㅡó acima do nó das folhas 
unifolioladas) e reprodutivos R6 (um nó com uma flor aberta) e R8 (um a três nós com vagem verde). Esse ensaio consistiu de dois tratamentos: a) controle (com Pi durante todo o período experimental); e b) supressão (supressão do Pi por dez dias, quando as plantas atingiram os estádios V3, V4, R6 e R8). Após o período de supressão, foram efetuadas as avaliações fisiológicas e as plantas foram coletadas para análise de Pi.

O segundo ensaio foi realizado para investigar os efeitos do ressuprimento de Pi durante os estádios V3, V4, R6 e R8. Esse ensaio também foi constituído de dois tratamentos: a) controle (com Pi durante todo o período experimental) e b) ressuprimento (sem Pi por dez dias, quando as plantas atingiram os estádios V3, V4, R6 e R8 e, posteriormente, as plantas foram transferidas para solução nutritiva contendo Pi na mesma concentração do tratamento controle, onde permaneceram por mais dez dias). Após o período de ressuprimento, foram efetuadas as avaliações fisiológicas e as plantas foram coletadas para análise de Pi.

Em cada ensaio, os tratamentos foram analisados dentro de cada estádio. Foram utilizadas parcelas de duas plantas por vaso, com quatro repetições, dispostas num delineamento experimental inteiramente casualizado. Os dados foram submetidos à análise de variância, a $5 \%$ de significância pelo teste $\mathrm{F}$.

A assimilação líquida de $\mathrm{CO}_{2}$ foi avaliada com analisador de gases a infravermelho portátil, em sistema aberto (LCA4, Analytical Development Co., Hoddesdon, UK), no folíolo central do terceiro trifólio superior, completamente expandido, a partir do ápice. Os vasos foram transferidos para uma sala sob condições controladas e as plantas foram aclimatadas por um período prévio de $30 \mathrm{~min}$ sob temperatura de aproximadamente $22^{\circ} \mathrm{C}$, umidade relativa do ar em torno de $80 \%$ e irradiância de 750 - $800 \mathrm{mmol}$ de fótons $\mathrm{m}^{-2} \mathrm{~s}^{-1}$.

A determinação da área do folíolo terminal utilizado para as medições da assimilação líquida do $\mathrm{CO}_{2}$ foi feita, fazendo-se incidir a luz de um "flash" de alta intensidade, em condições de baixa luminosidade ambiente, sobre o folíolo colocado entre o papel fotográfico e uma lâmina de vidro. A área escura do papel, correspondente ao limbo foliar e não influenciada pela luz, foi posteriormente determinada em um medidor de área foliar (Delta-T Devices, Burwell, Cambridge, UK). O mesmo folíolo usado para avaliar a assimilação líquida do $\mathrm{CO}_{2}$ foi utilizado para se determinar a cinética da emissão da fluorescência rápida da clorofila $a$, com um fluorômetro portátil (PEA-Plant Efficiency Analiser, Hanstech, King's Lynn, Norkfolk, UK). Foram determinadas a fluorescência inicial $\left(F_{o}\right)$, a fluorescência máxima $\left(\mathrm{F}_{\mathrm{m}}\right)$, a fluorescência variável $\left(\mathrm{F}_{\mathrm{v}}\right)$ e a eficiência fotoquímica do FS II $\left(\mathrm{F}_{\mathrm{v}} / \mathrm{F}_{\mathrm{m}}\right)$. Antes das medições, as folhas foram adaptadas ao escuro por um período de $30 \mathrm{~min}$.

Os teores de clorofilas foram determinados em trifólios localizados imediatamente abaixo daqueles utilizados para as medições de fotossíntese e fluorescência. A extração foi realizada em almofariz e pistilo com acetona $80 \%$ (ARNON, 1949). O extrato cetônico foi utilizado para as determinações da absorvância a 647, 663 e $470 \mathrm{~nm}$. As concentrações de clorofila $a, b$ e carotenóides foram calculadas com o uso das fórmulas propostas por LICHTENTHALER (1987).

Os teores de $\mathrm{Pi}$ foram determinados no terceiro trifólio superior, completamente expandido, a partir do ápice, utilizando-se o método proposto por SMILLE \& KROTKOV (1960) e adaptado por HOUGE et al. (1970). As amostras foram coletadas, pesadas e imersas em $2,0 \mathrm{~mL}$ de $\mathrm{HClO}_{4} 0,2 \mathrm{~N}$, seguindo-se o congelamento a $-15^{\circ} \mathrm{C}$. $\mathrm{O}$ extrato foi obtido da maceração do material vegetal em almofariz e pistilo, utilizando $\mathrm{HClO}_{4} 0,2 \mathrm{~N}$. O macerado foi centrifugado a $3.000 \mathrm{~g}$ por $10 \mathrm{~min}$ e o sobrenadante acondicionado em balão volumétrico de $25 \mathrm{~mL}$, sendo o precipitado ressuspenso e centrifugado por mais duas vezes. O volume final foi ajustado para $25 \mathrm{~mL}$. Alíquotas do sobrenadante foram utilizadas para a reação com molibdato de amônio e posterior determinação dos teores de Pi (LINDEMAN, 1958).

\section{RESULTADOS E DISCUSSÃO}

Observou-se redução significativa nos teores de Pi nas folhas das plantas sob supressão de fósforo, em relação às do tratamento controle em todos os estádios do desenvolvimento (Figura 1a). Resultados similares foram observados na matéria fresca da parte aérea em Glycine max (SILVA, 1998), o mesmo ocorrendo com o Pi total em Medicago sativa (DREVON \& HARTWING, 1997), Vigna radiata $\mathrm{e}$ Vigna aconitifolia (CHAUDHARY \& FUJTTA, 1998). Sob supressão, os teores de Pi obtidos no presente ensaio, foram superiores aos encontrados em plantas de Glycine max submetidas a sete dias de supressão de $\mathrm{Pi}$, que variaram de 0,2 a $0,5 \mathrm{mg}$ de $\mathrm{Pi} \mathrm{g}^{-1}$ matéria fresca (SILVA, 1998). Isso demonstra que houve adequada mobilização de outras reservas não metabólicas (vacúolos) e metabólicas das folhas mais velhas para as folhas amostradas, sustentando a 


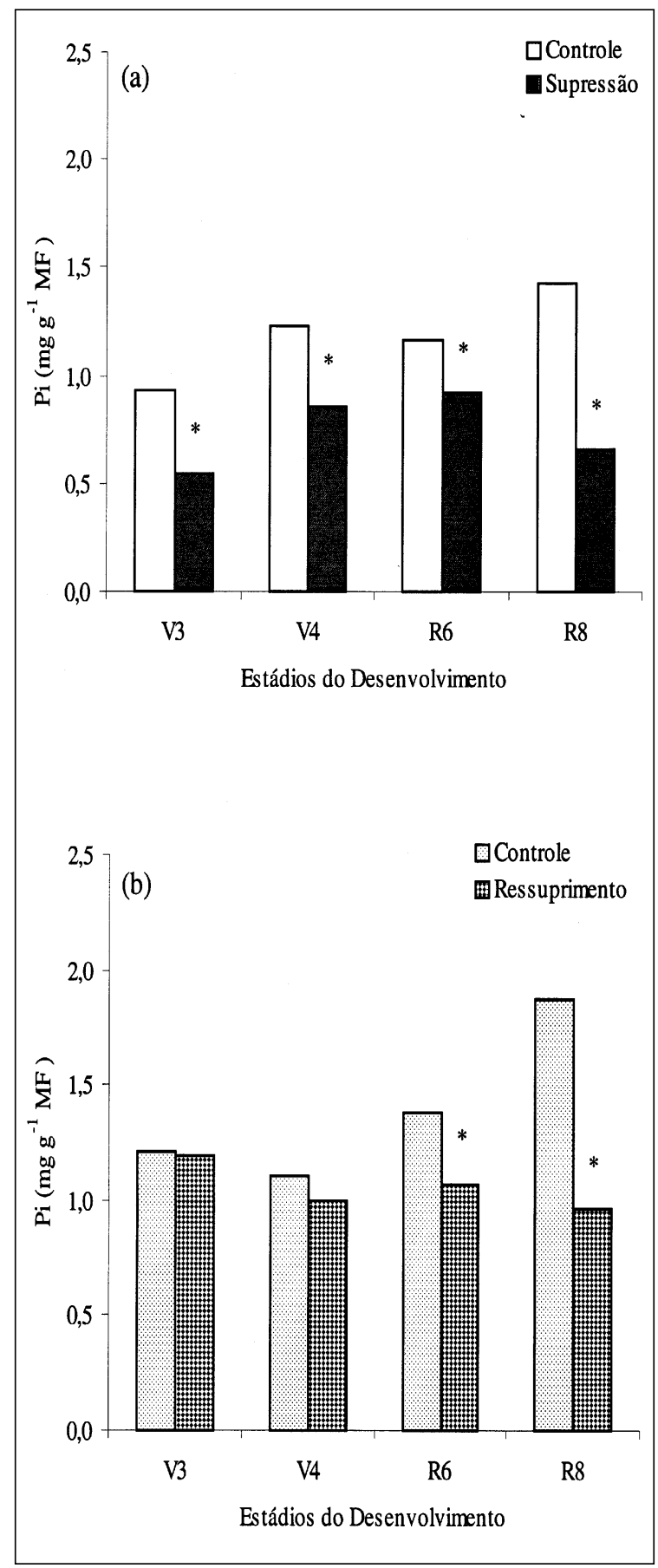

Figura 1 - Teores de fósforo (Pi) na matéria fresca (MF) de folha de plantas de Medicago sativa sob supressão (a) ressuprimento (b) de fósforo, nos estádios V3, V4, R6 R8. (*) Diferença significativa a $5 \%$ de probabilidade $\mathrm{d}$ erro, pelo teste $\mathrm{F}$, em cada estádio.

hipótese do papel dos vacúolos na manutenção da homeostase do Pi citoplasmático nas células do mesófilo, quando sob deficiência de Pi (MIMURA et al., 1990; MIMURA, 1995). Após o ressuprimento, os teores de Pi nas folhas nos estádios V3 e V4 (Figura $1 \mathrm{~b})$ alcançaram valores similares aos dos tratamentos controles. Entretanto, a ausência de resposta nos estádios R6 e R8, provavelmente ocorreu em razão da queda na absorção e, ou, maior translocação de Pi das folhas amostradas ou do Pi absorvido, diretamente para as flores e frutos (Figura $1 \mathrm{~b}$ ).

Os teores de clorofilas $a, b$ e de carotenóides nas plantas sob supressão de Pi não apresentaram diferenças significativas em relação aos das plantas do tratamento controle, em todos os estádios do desenvolvimento (dados não mostrados). Embora os teores de Pi nas folhas sob supressão tenham sido significativamente menores em relação aos das plantas do tratamento controle, essa redução provavelmente não influenciou a biossíntese ou a degradação de clorofilas $a, b$ e de carotenóides. A invariabilidade nos teores dos pigmentos fotossintéticos pode refletir-se na manutenção da captação de luz pelo sistema-antena do fotossistema I (LHC I) e fotossistema II (LHC II) e na capacidade de transferência de elétrons na cadeia fotossintética (BUTLER, 1977). A deficiência de Pi nem sempre altera as concentrações de clorofilas e carotenóides, a exemplo de plantas de Phaseolus vulgaris (SAWADA et al., 1983), de Glycine max (FREDEEN et al., 1989; CRAFTS-BRANDNER, 1992a) e de Zea mays (USUDA \& SHIMOGAWARA, 1991, 1992). Contudo, plantas jovens de Helianthus annuus sob deficiência de Pi apresentaram decréscimos no conteúdo de clorofilas e carotenóides em relação às plantas sob condições de suprimento ótimo de $\mathrm{Pi}$ (PLESNICAR et al., 1994). Essas diferenças registradas na literatura, sobre os efeitos da deficiência de Pi nos teores de pigmentos fotossintéticos, parecem mais relacionadas com o período de duração do estresse de Pi que com a diferença entre espécies. Após o ressuprimento de $\mathrm{Pi}$, os teores de clorofilas $a, b$ e carotenóides mantiveram a mesma tendência do ensaio de supressão de Pi.

A cinética de emissão de fluorescência rápida, avaliada pela $F_{o}, F_{m}$, e pela razão $F_{v} / F_{m}$, uma medida de eficiência fotoquímica do FS II, de maneira geral, não apresentou mudanças significativas após o período de supressão de Pi em relação ao das plantas do tratamento controle. $\mathrm{A} \mathrm{F}_{\mathrm{o}}$ somente apresentou um aumento significativo, de $18 \%$, no estádio V4 das plantas sob supressão de $\mathrm{Pi}$, em relação ao das plantas do tratamento controle (Figura 2a); contudo, esse aumento não foi suficiente para alterar a razão $F_{v} / F_{m}$, (Figura $2 e$ ). Esse fato, provavelmente, foi proveniente da 

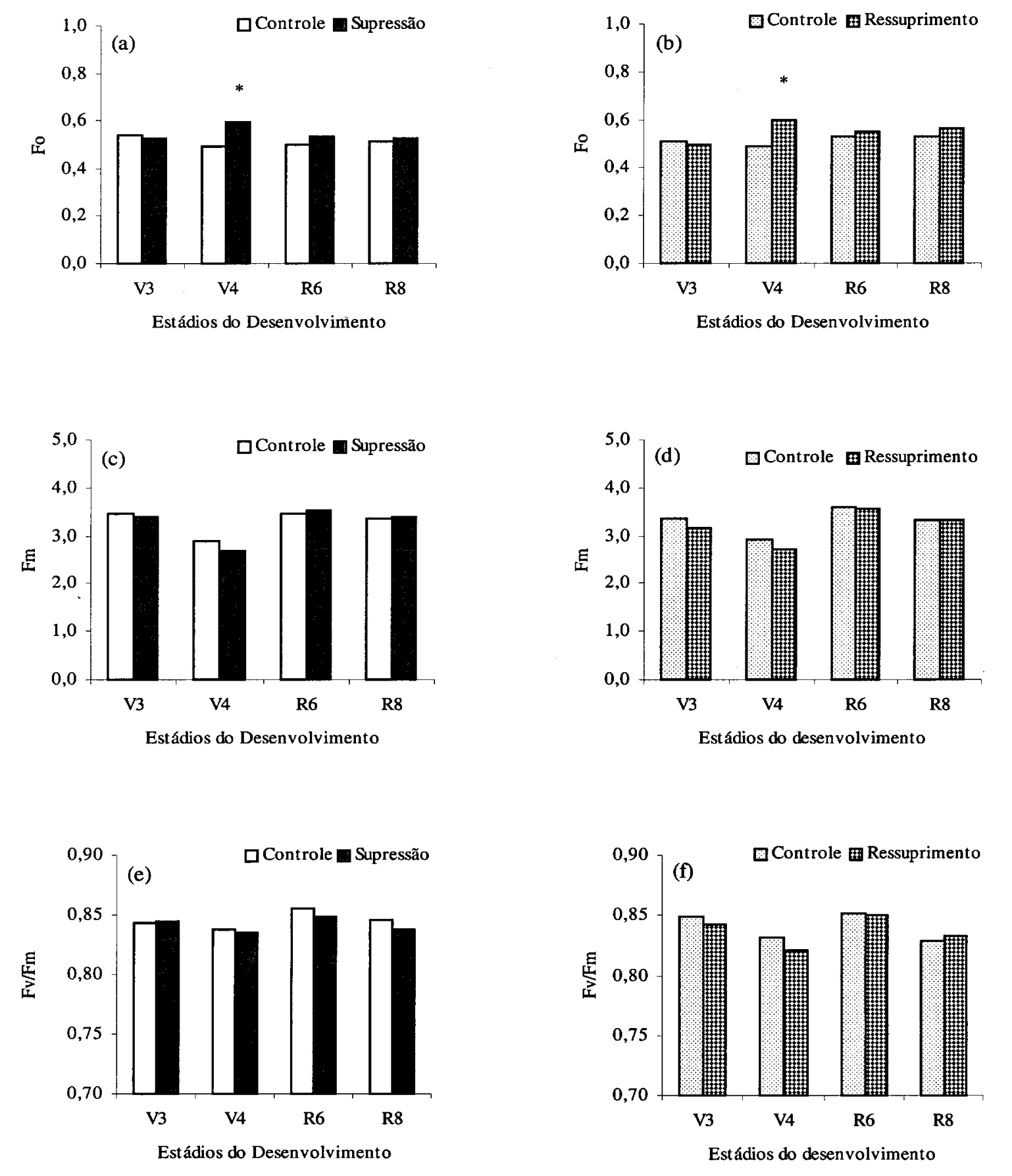

Figura 2 - Fluorescência inicial $\left(\mathrm{F}_{\mathrm{o}}\right)$, fluorescência máxima $\left(\mathrm{F}_{\mathrm{m}}\right)$ e a eficiência fotoquímica do fotossistema II $\left(\mathrm{F}_{\mathrm{v}} / \mathrm{F}_{\mathrm{m}}\right)$ no folíolo central do terceiro trifólio completamente expandido de plantas de Medicago sativa sob supressão (a, c, e) e ressuprimento (b, d, f) de fosfato, nos estádios V3, V4, R6 e R8. (*) Diferença significativa a 5\% de probabilidade de erro, pelo teste F, em cada estádio.

redução de $8 \%$ da $\mathrm{F}_{\mathrm{m}}$ nas plantas sob supressão de Pi em relação ao controle, nesse mesmo estádio (Figura 2c). Aumentos em $\mathrm{F}_{\mathrm{o}}$ podem ocorrer quando há algum dano no centro de reação do FS II, ou por uma redução na transferência de energia de excitação do sistema coletor de luz para o centro de reação (OUZOUNIDOU, 1993).

De modo geral, pode-se inferir, pelos resultados deste ensaio, que a cultivar Flórida 77 possui alta tolerância à redução na disponibilidade de

Ciência Rural, v. 33, n. 5, set-out, 2003. 
$\mathrm{Pi}$, pelo menos por um período de dez dias, em se tratando da eficiência fotoquímica do FS II. A ausência de mudanças na razão $F_{v} / F_{m}$ sob supressão de Pi para essa cultivar (Figura 2e) pode estar relacionada com a manutenção nos teores de clorofilas $a$ e $b$ e carotenóides. Com o ressuprimento de $\mathrm{Pi}$, todos os parâmetros da cinética de emissão de fluorescência seguiram a mesma tendência do ensaio de supressão, mostrando que as mobilizações intracelular e, talvez, intercelular do Pi foram suficientes para não alterar essas características (Figuras 2b, d, f).

A taxa fotossintética por área foliar, avaliada pela assimilação líquida do $\mathrm{CO}_{2}$, mostrou decréscimos significativos nas plantas sob supressão de Pi, em todos os estádios do desenvolvimento (Figura 3a). A redução na taxa fotossintética pode estar diretamente relacionada com os menores teores de Pi nas plantas sob supressão de Pi (Figura 1a). Plantas de Spinacia oleracea (BROOKS, 1986), de Zea mays (USUDA \& SHIMOGAWARA, 1991), de Helianthus annuus (JACOB \& LAWLOR, 1992), de Glycine max (GUIDI et al., 1994) e de Phaseolus vulgaris (KONDRACKA \& RYCHTER, 1997) sob baixos níveis de $\mathrm{Pi}$, apresentaram decréscimos significativos na taxa de assimilação líquida do $\mathrm{CO}_{2}$. Resultados similares também foram observados em plantas de Glycine max sob supressão de Pi por sete dias, tanto nos estádios vegetativos quanto nos reprodutivos (SILVA, 1998). Após o ressuprimento, apenas as plantas no estádio V3 não alcançaram valores similares aos das plantas do tratamento controle (Figura 3b).

O nível de Pi limitante para a taxa fotossintética é variável, conforme a espécie (FOYER \& SPENCER, 1986). O decréscimo na taxa fotossintética em razão da deficiência de Pi pode estar relacionado com a redução na quantidade e na atividade da rubisco, ou com o decréscimo na síntese da RuBP, ou, ainda, com o decréscimo no fluxo de Pi para o interior do cloroplasto (BROOKS, 1986; PLESNICAR et al., 1994). Em plantas de Helianthus annuus e Zea mays, foi observado que a deficiência de Pi diminuiu o conteúdo de RuBP, enquanto a atividade específica da rubisco foi significativamente reduzida em Helianthus annuus, mas o mesmo não aconteceu com plantas de Zea mays (JACOB \& LAWLOR, 1992).

Além disso, a formação da RuBP nas plantas sob baixos níveis de Pi não parece ser limitada pelo suprimento de ATP e NADPH, em função da elevada relação ATP/ADP e NADPH/NADP ${ }^{+}$ em plantas sob condições de baixa disponibilidade de Pi (FREDEEN et al., 1990). O decréscimo na taxa de formação da RuBP tem

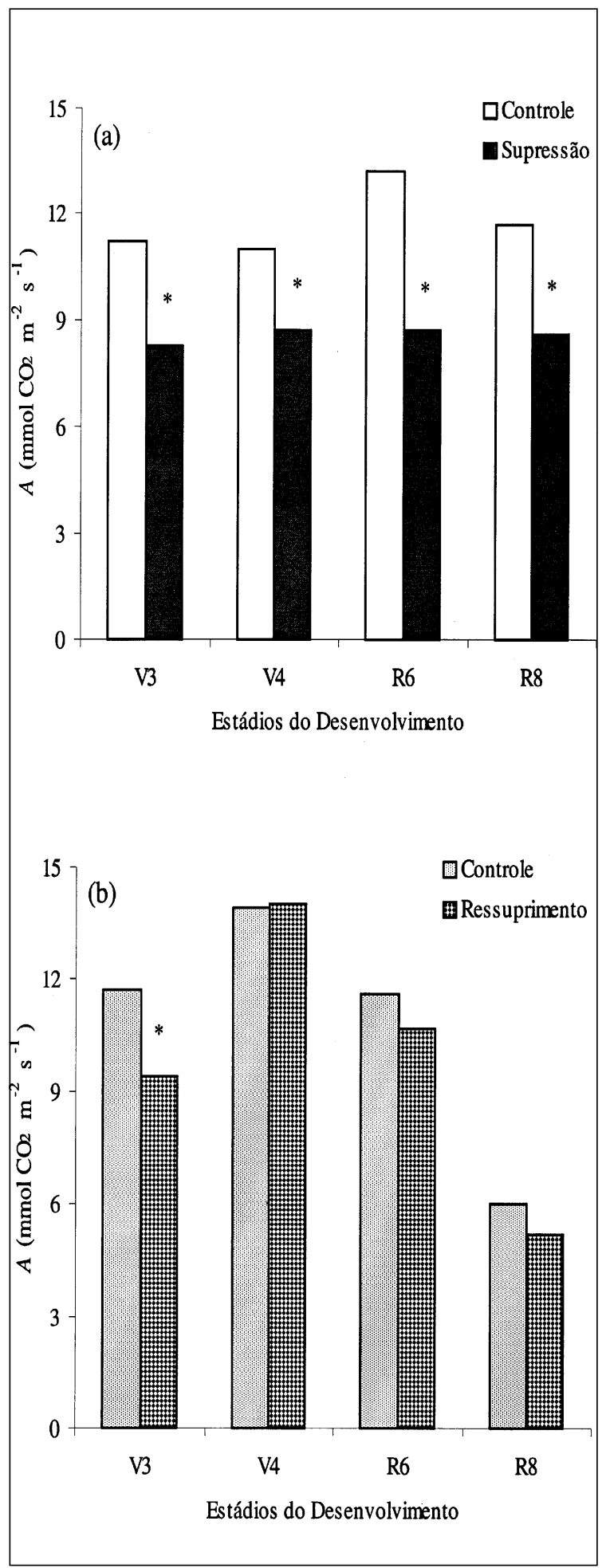

Figura 3 - Assimilação líquida de $\mathrm{CO}_{2}(A)$ no folíolo central do terceiro trifólio completamente expandido de plantas de Medicago sativa sob supressão (a) e ressuprimento (b) de fosfato, nos estádios V3, V4, R6 e R8. (*) Diferença significativa a $5 \%$ de probabilidade de erro, pelo teste $\mathrm{F}$, em cada estádio. 
sido atribuído a menor atividade de certas enzimas do cloroplasto, em folhas de plantas submetidas a baixos níveis de $\mathrm{Pi}$, como, por exemplo, a cinase da ribulose-5-fosfato (RAO \& TERRY, 1995).

Os resultados obtidos neste estudo sugerem que a redução na taxa fotossintética relaciona-se mais com a etapa bioquímica que com a etapa fotoquímica da fotossíntese. Essa afirmativa baseia-se principalmente na ausência de diferenças significativas na eficiência fotoquímica do fotossistema II (Figura 2e), sugerindo que a síntese de ATP e de poder redutor (NADPH) não foi influenciada pela deficiência de Pi. Resultados similares foram observados em plantas de Helianthus annuus, em que o transporte de elétrons fotossintético através do FS II não limitou a fotossíntese, e a redução na taxa fotossintética foi atribuída, principalmente, à diminuição da eficiência de síntese da RuBP (PLESNICAR et al., 1994).

\section{CONCLUSÕES}

O período de supressão de fósforo por dez dias em plantas de Medicago sativa, somente afetou negativamente a assimilação do $\mathrm{CO}_{2}$, enquanto que a eficiência fotoquímica não foi alterada. De modo geral, com o ressuprimento, as plantas não perderam sua capacidade de recuperação.

\section{REFERÊNCIAS BIBLIOGRÁFICAS}

ARNON, D.I. Copper enzymes in isolated chloroplast. Polyphenoloxidase in Beta vulgaris. Plant Physiology, Rockville, v.24, n.1, p.1-15, 1949.

BROOKS, A. Effects of phosphorus nutrition on ribulose 1,5bisphosphate carboxylase activation, photosynthetic quantum yield and amounts of some Calvin cycle metabolites in spinach leaves. Australian Journal of Plant Physiology, Collingwood, v.13, p.221-237, 1986

BUTLER, W.L. Chlorophyll fluorescence: a probe for electron transfer and energy transfer. In: TREBST, A.; AVRON, M. (Eds). Encyclopedia of plant physiology. New York : n.i., 1977. V.5, p.149-167.

CHAUDHARY, M.I.; FUJITA, K. Comparison of phosphorus deficiency effects on the growth parameters of mashbean, mungbean, and soybean. Soil Science and Plant Nutrition, Tóquio, v.44, n.1, p.19-30, 1998.

CRAFTS-BRANDNER, S.J. Phosphorus nutrition infuence on leaf senescence in soybean. Plant Physiology, Rockville, v.98, n.3, p.1128-1132, 1992a.

CRAFTS-BRANDNER, S.J. Phosphorus nutrition influence on starch and sucrose accumulation, and activities of ADP-glucose pyrophosphorylase and sucrose-phosphate sinthase during the grain filling period in soybean. Plant Physiology, Rockville, v.98, n.3, p.1133-1138, 1992b.

DREVON, J.J., HARTWING, V.A. Phosphorus deficiency increases the argon-induced decline of nodule nitrogenase activity in soybean and alfalfa. Planta, Berlin, v.201, n.4, p.463-469, 1997.

FOYER, C.; SPENCER, C. The relationship between phosphate status and photosynthesis in leaves. Effects on intracellular orthophosphate distribution, photosynthesis and assimilate partitioning. Planta, Berlin, v.167, p.369-375, 1986.

FREDEEN, A.L. et al. Effects of phosphorus nutrition on photosynthesis in Glicyne $\max$ (L.) Merr. Planta, Berlin, v.181, p.399-405, 1990

FREDEEN, A.L.; RAO, I.M.; TERRY, N. Influence of phosphorus nutrition on growth and carbon partitioning in Glycine max. Plant Physiology, Rockville, v.89, p.225-230, 1989.

GUIDI, L.; PALLINI, M.; SOLDATINI, G.F. Influence of phosphorus deficiency on photosynthesis in sunflower and soybean plants. Agrochimica, Pisa, v.38, n.3, p.211-222, 1994.

HOAGLAND, D.R.; ARNON, D.I. The water culture method for growing plants without soil. California : California Agricutural Experimental Station, 1950. 32p. (Circular, 347).

HOUGE, E.; WILCOX, G.E.; CANTLIFFE, D.J. Effect of soil phosphorus level on phosphate fractions in tomato leaves. Americam Society for Horticultural Science Journal, Alexandria, v.95, p.174-176, 1970.

JACOB, J.; LAWLOR, D.W. Dependence of photosynthesis of sunflower and maize leaves on phosphate supply, ribulose1,5-bisphosphate carboxylase/oxygenase activity, and ribulose-1,5-bisphosphate pool size. Plant Physiology, Rockville, v.98, n.3, p.801-807, 1992

KHAMIS, S.; CHAILLOU, S.; LAMAZE, T. $\mathrm{CO}_{2}$ assimilation and partitioning of carbon in maize plants deprived of orthophosphate. Journal of Experimental Botany, Oxford, v.41, n.233, p.1619-1625, 1990.

KONDRACKA, A.; RYCHTER, A.M. The role of Pi recycling processes during photosynthesis in phosphate-deficient bean plants. Journal of Experimental Botany, Oxford, v.48, n.312, p.1461-1468, 1997.

KRAUSE, G.H.; WEIS, E. Chlorophyll fluorescence and photosynthesis: the basic. Annual Review of Plant Physiology and Plant Molecular Biology, Palo Alto, v.42, p.313-349, 1991.

LICHTENTHALER, H.K. Chlorophylls and carotenoids: pigments of photosynthetic biomembranes. In: COLOWICK, S.P.; KAPLAN, N.O. (Eds). Methods in enzymology, San Diego, v.148, p.350-382, 1987.

LINDEMAN, W. Observations on the behavior of phosphate compunds in Chorela at the transition from dark to light. In: INTERNATIONAL CONFERENCE ON THE PEACEFUL USES OF ATOMIC ENERGY. 1958, New York. Proceedigns... New York : Academic, 1958. V.24, n.1, p.8-15.

MIMURA, T. et al. Phosphate transport across biomembranes and cytosolic phosphate homeostasis in barley leaves. Planta, Berlin, v.180, p.139-146, 1990 
MIMURA, T. Homeostasis and transport of inorganic phosphate in plants. Mini Review. Plant and Cell Physiology, Kyoto, v.36, n.1, p.1-7, 1995.

OUZOUNIDOU, G. et al. Changes in variable chlorophyll fluorescence as a result of Cu-treatment: dose-response relations in Silene and Thaspi. Photosynthetica, Dordrecht, v.29, n.3, p.455-462, 1993.

PLESNICAR, M. EPhotosynthesis and chlorophyll fluorescence in sunflower (Helianthus annuus L.) leaves as affected by phosphorus nutrition. Journal of Experimental Botany, Oxford, v.45, n.276, p.919-924, 1994.

QIU, J.; ISRAEL, D.W. Carbohydrate accumulation and utilization in soybean plants in response to altered phosphorus nutrition. Plant Physiology, Rockville, v.90, p.722-728, 1994.

RAO, M.; TERRY, N. Leaf phosphate status, photosynthesis and carbon partitioning in sugar beet. I. Changes in growth, gas exchange and Calvin cycle enzymes. Plant Physiology, Rockville, v.90, p.814-819, 1989.

RAO, M.; TERRY, N. Leaf phosphate status, photosynthesis, and carbon partitioning in sugar beet. Plant Physiology, Rockville, v.107, p.1313-1321, 1995.
SAWADA, S.; IGARASHI, T.; MIYACHI, S. Effects of phosphate nutrition on photosynthesis, starch and total phosphorus level in single rooted leaf of dwarf bean. Photosynthetica, Dordrecht, v.17, n.4, p.484-490, 1983.

SILVA, D. M. Crescimento, fotossíntese e metabolismo do nitrogênio em plantas de soja noduladas sob omissão e ressuprimento de fósforo. 1998. 117f. Tese (Doutorado em Fisiologia Vegetal) - Curso de Pós-graduação em Fisioloogia Vegetal, Universidade Federal de Viçosa.

SMILLIE, R.M.; KROTKOV, G. The estimation of nucleic acids in some algae and higher plants. Canadian Journal of Botany, Ottawa, v.38, p.31-49, 1960.

USUDA, H.; SHIMOGAWARA, K. Phosphate deficiency in maize. II. Enzyme activities. Plant and Cell Physiology, Kyoto, v.32, n.8, p.1313-1317, 1991.

USUDA, H.; SHIMOGAWARA, K. Phosphate deficiency in maize. III. Changes in enzyme activities during the course of phosphate deprivation. Plant Physiology, Rockville, v.99, n.4, p.1680-1685, 1992.

VINCENT, J.M. A manual for the practical study of the rootnodule bacteria. London : Blackwell Scientific, 1970. 164p. (IPB Handbook, n. 15). 